\title{
The Correlation of IFN $\gamma$ to the Preferential Isolation of Influenza Type B over Type A Viruses in Madin Darby Canine Kidney Cells
}

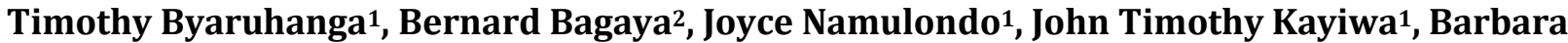 \\ Namagambo', Nicholas Owor ${ }^{1}$, Irene Nabukenya', Barnabas Bakamuntumaho', Julius Julian \\ Lutwama ${ }^{1}$
}

${ }^{1}$ Department of Arbovirology, Uganda Virus Research Institute, Entebbe, Uganda

${ }^{2}$ College of Health Sciences, Makerere University, Kampala, Uganda

Email: tssekandi@gmail.com

How to cite this paper: Byaruhanga, T., Bagaya, B., Namulondo, J., Kayiwa, J.T., Namagambo, B., Owor, N., Nabukenya, I., Bakamuntumaho, B. and Lutwama, J.J. (2017) The Correlation of IFN $\gamma$ to the Preferential Isolation of Influenza Type B over Type A Viruses in Madin Darby Canine Kidney Cells. Open Journal of Medical Microbiology, 7, 12-28.

https://doi.org/10.4236/ojmm.2017.71002

Received: November 11, 2016

Accepted: February 6, 2017

Published: February 9, 2017

Copyright ( 92017 by authors and Scientific Research Publishing Inc. This work is licensed under the Creative Commons Attribution International License (CC BY 4.0).

http://creativecommons.org/licenses/by/4.0/

\begin{abstract}
The isolation of influenza viruses in Madin Darby Canine Kidney (MDCK) cells has shown preferential isolation of a great percentage of Influenza B strains at the first passage than Influenza A strains. During in vitro isolation of Influenza viruses, majority of type A viruses are not confirmed as positive isolates by Hemagglutination (HA) assay despite having higher virulence and pathogenicity versus influenza B viruses. This study investigated the differences in IFN- $\gamma$ and IL-10 cytokines secreted by MDCK cells upon exposure to the viruses and thus provided possible answers as to why influenza type B can easily be isolated from MDCK cells compared to influenza A. Positive influenza viruses were inoculated onto MDCK cells. IFN- $\gamma$ and IL-10 cytokines stimulated by the viruses in MDCK cells were measured by indirect ELISA at 1 hour, 12 hours, 48 hours and 72 hours post inoculation (pi). A total of 46 specimens, with 23 specimens from each virus type were analyzed. IFN- $\gamma$ was significantly higher at 1 hour pi in MDCK cells for influenza type A at $\mathrm{p}$ value of 0.024 than type B. No statistical significance was observed in means of cytokine IL-10 between influenza type A and type B. The study may show that IFN- $\gamma$ is correlated to the preferential isolation of influenza type B over type A viruses. Anti-inflammatory cytokines may not necessarily be playing a role in the preferential growth of influenza type $B$, a less virulent type over influenza type A in MDCK cells.
\end{abstract}

\section{Keywords}

Interferon Gamma, Influenza A, Influenza B, Isolation

\section{Background}

Influenza, commonly known as "flu" is a highly contagious airborne viral dis- 
ease. The disease is caused by three influenza types; that is, Influenza A, B and C all of which are classified under the family Orthomyxoviridae. Influenza type A viruses infect several host species from birds to mammals, and simultaneous infection with different strains has also been shown to occur. In other cases, both influenza $A$ and $B$ viruses undergo significant antigenic drift, though there is lower evolutionary rate in influenza B compared to influenza A [1]. Although influenza B virus infection can occasionally be severe and even fatal, the clinical picture of the disease is usually milder than that caused by type A viruses [1] [2]. The virus can easily spread from person to person through aerosol droplets, however, other influenza virus strains like influenza A (H5N1) (also known as avian influenza) can spread from birds (avian species) to humans through direct contact with the diseased bird. The influenza A types are further sub-divided into strains dependent on the hemagglutinin (HA) and neuraminidase (NA) proteins of the virus capsid. At the present time, there are $18 \mathrm{HA}$ and $11 \mathrm{NA}$ which can undergo re-assortment or mutations to give rise to new or variant strain among influenza type A viruses. It was in this regard that strains such as the case of influenza B had formed a homogeneous group, which started to diverge antigenically into two distinct lineages, whose first representatives were B/Victoria/2/87 and B/Yamagata/16/88, as the Victoria and Yamagata lineages respectively [3]. This nomenclature system was adapted after the World Health Organization (WHO) where B denotes for the type of Influenza virus, Victoria as the place of origin, 2 as the strain serial number and 87 as the year of isolation. A similar nomenclature system exists for influenza A viruses [4].

In 1918 an influenza pandemic claimed over 40 million people around the globe; many more than those who died in World War I [5] [6] [7]. There have also been other pandemics, namely: the Asian Influenza (A/H2N2) of 1957, Hong Kong Influenza A (H3N2) of 1968 [3]. The global burden of influenza is believed to cause 300,000 deaths annually [5]. The virus is associated with high morbidity and mortality especially among persons aged $>65$ years, children aged $<2$ years, and people who have medical conditions that place them at increased risk of developing complications from influenza [8] and other respiratory infections. In Uganda, work done by Balinandi et al. 2013 [9] showed that influenza viruses type A and B accounted for $21.4 \%$ of Influenza Like Illness (ILI) cases among Respiratory infections.

The influenza isolation rate is assessed by hemagglutination (HA) and hemagglutination inhibition (HI) assays. The isolated viruses can now then be used in vaccine manufacture, which is important in controlling seasonal influenza around the year. The difference in the isolation rate of influenza virus types, $\mathrm{A}$ and $B$ creates an opportunity to investigate the factors driving such a significant phenomenon.

Influenza virus type $A$ is known to be more virulent and pathogenic compared to Influenza virus type B. During in vitro culture isolation of Influenza viruses, majority of type A viruses are hardly isolated at the first passage in MDCK cells. This delays Influenza virus isolation and vaccine production processes. More so 
this does not conform to the known higher virulence and pathogenicity of the influenza A versus influenza B viruses. The continuous annual need for seasonal influenza vaccine necessitates rapid virus isolation to provide potential vaccine candidates for a particular season. The MDCK cell line remains the most suitable in-vitro culture system for isolation, characterization and propagation of Influenza viruses but the difficulty to grow type A viruses renders the process cumbersome and lengthy. Influenza viruses are currently among the infectious diseases and zoonoses threatening global populations, making it urgent to refine methods for expedited isolation and characterization of suspected Influenza infections. Cellular responses to viruses involve production of a wide range of cytokines, such as IFN- $\gamma$ that stimulate cells to suppress protein synthesis and cytoplasmic transport which in turn would affect viral packaging. Whether differences in cytokine induction between Influenza A and B are contributing factors to their differences in propagation in MDCK cells remains unknown. This study therefore investigated differences in IFN- $\gamma$ and IL-10 cytokines secreted by MDCK cells upon exposure to influenza type A and type B viruses to provide possible answers as to why influenza type $B$ can easily be isolated from MDCK cells compared to influenza A yet they are of the same family, Orthomyxoviridae.

Null hypothesis: There is no difference in the mean cytokine secretion by MDCK cells between influenza type A and type B. Alternative hypothesis: There is a difference in the amount soluble factors produced by MDCK cells upon exposure to different influenza virus types.

It is likely that a factor more prominent in Influenza B viruses favors the growth and isolation of Influenza B viruses than Influenza A under similar conditions. This would have significant effects on the infectivity of a virus strain and provide possible alternatives to vaccines as well. Identification of such factor(s) would provide information and expound on other possible methods of influenza virus growth and isolation. It will also provide a platform for further research to improve on the isolation rate of Influenza type A viruses and thus reduce the time taken to carry out antigenic characterization of the virus for the provision of vaccine strain candidates. This time lag is of public health importance and is costly in terms of efficient vaccine availability to reduce the spread of influenza which proves a threat due to anticipated outbreaks of highly pathogenic avian influenza viruses. Timely production and availability of the vaccine is the first effective way of patient management.

Objective: To determine why there is preferential isolation of influenza type $B$ over Influenza type A in MDCK cell line cultures by characterizing Influenza type A and type B-dependent cytokine responses (IFN $\gamma$ and IL-10) induced in MDCK cell lines using the ELISA technique.

This research sought to answer why influenza type B virus expresses early during cell infection, if there was a cytokine stimulation difference between influenza type A and B and whether this difference is associated with the severity of the virus.

Cytokine profiles during influenza 
Cytokines have been implicated to play a major role in the onset of clinical symptoms associated with influenza and significantly diminish during recovery. The most implicated cytokines include interferon-alpha (IFN- $\alpha$ ), tumor necrosis factor $\alpha$ (TNF- $\alpha$ ), interleukin-1 (IL-1) $\alpha / \beta$. These cytokines are usually followed by an increase in IL-6, neutrophil attracting interleukin-8 (IL-8), macrophage inflammatory proteins (MIP) and monocyte chemoattractant proteins [10]. The clinical symptoms associated with these cytokines include anorexia, sleepiness and lethargy. The cytokines are also more localized than systemic, implying that they are specific and induced for the particular areas affected, for example, in a study using human volunteers, higher levels of IFN- $\alpha$, TNF- $\alpha$ and IL- 6 were observed in respiratory tract secretions than in serum or plasma [11] [12]. The role and importance of each cytokine has been elaborated in several studies such as injection of TNF- $\alpha$ antibodies in murine model reduced lung lesion and prolonged survival by 24 hours [13], IFN- $\alpha$ and IL-1 are important in fever responses [14]. It is also important to note that these very cytokines of interest in influenza disease express redundancy where by absence of one cytokine or knock out of a gene expressing the cytokine will be compensated for by another cytokine. This phenomenon is observed between IFN- $\alpha$, TNF- $\alpha$, IL- 1 and IL-6. On the other hand, anti-inflammatory cytokines such as IL-4 have been shown to cause delayed influenza virus clearance in infected mice and in vitro, IL- 4 was associated with the lower levels of IFN- $\gamma$ in the infected cells [15]. It remains unclear whether the ability of influenza $A$ to evade early immune responses is due to the ability of the NS1 protein to interfere with the expression of INF and thus accumulation of the virus or it is the release of anti-inflammatory cytokines that theoretically favor un-checked virus multiplication. In this regard, cytokines play a significant role in severity of influenza infection but no study has been done to estimate the levels of cytokines induced in any experimental model versus infectivity in comparison of influenza A and B.

\section{Influenza infectivity in relation to cytokines and cellular pathway}

Virus infectivity can be defined as the characteristics of the virus that enable it to enter upon exposure, survive and multiply or replicate in a susceptible host and thus cause an infection. IFN has been shown to participate in the restriction of virus replication and the initiation of immune responses [2] [16]. The activation of the innate immune system during viral infection is triggered mainly by the recognition of viral nucleic acids. However, some viral protein structures have also been reported to induce an antiviral response, such as inflammasome activation by the influenza A virus M2 protein [7], others activate protein kinase (PKR) in influenza B virus vRNP [17]. Genomic viral RNAs (vRNAs), as well as RNA replication and transcription products, are potent activators of innate immune responses. The classical receptors responsible for vRNA recognition are RIG-I for the triphosphorylated RNA structures, Toll-like receptor 3 (TLR3) for the dsRNA, and TLR 7/8 for the ssRNA molecules [18] [19]. Different types of vRNA molecules are produced during influenza virus infection, and total cellular RNA from virus-infected cells has been shown to be a potent inducer of IFN 
responses when transfected into cells. While RIG-I is considered to be the most important vRNA sensor, another RIG-I-like receptor, MDA5, has been reported to recognize longer and higher-order RNA structures [1] [20]. Whereas the RIG-I pathway is dominant in influenza A virus infection, influenza $B$ virus is recognized by MDA5, suggesting that different RNA sensors play differential roles in the recognition of various types of viruses [1] [21].

\section{Materials and Methods}

\section{Study design}

This laboratory-based experimental study utilized leftover PCR-confirmed positive influenza type A and B viruses. These specimens were collected as clinical nasal pharyngeal and or oral pharyngeal swabs.

\section{Study population, site and period}

The population was patients who presented with signs and symptoms that met the case definitions of Influenza-Like Illness (ILI) and Severe Acute Respiratory Infections (SARI) [22]. The sample collection was done at the 11 health facilities selected to serve as Influenza sentinel surveillance sites in Uganda; Entebbe Hospital, Kitebi Health Center III, Kawaala Health Center III, Mbarara Regional Referral Hospital, Fort Portal Regional Referral Hospital, Arua Regional Referral Hospital, Koboko Health Center IV, Ludara Health Center III and Tororo Regional Referral Hospital. The samples were transported in Liquid Nitrogen to the Uganda Virus Research Institute (UVRI)/National Influenza Center (NIC), Entebbe, for Influenza Surveillance. UVRI hosts the NIC under the department of Arbovirology. This laboratory carries out detection by PCR and isolation of Influenza viruses. The locations of the different sentinel sites are shown in Figure 1. This study was conducted from August 2015 to May 2016.

\section{Sample size}

The hypothesis comparing the means of the outcome variable (average means of the total INF gamma and IL-10 produced by the MDCK cells in response to infection with influenza $A$ and $B$ ) in the two independent populations (influenza $A$ and influenza B) was considered. The hypotheses were comparing between the null versus alternative hypothesis as shown below:

$$
\mathrm{H}_{0}: \mu_{1}=\mu_{2 \text { versus }} \mathrm{H}_{1}: \mu_{1} \neq \mu_{2}
$$

where $\mu_{1}$ and $\mu_{2}$ are the means in the two comparison populations. The hypothesis of interest is the alternative $\mathrm{H}_{1}$. The outcome variables are continuous and of quantitative nature and thus the formula to detect difference in means is given as:

$$
\frac{n_{i}=\left(Z_{a / 2}+Z_{\beta}\right)^{2} \times 2 \times \sigma^{2}}{\mathrm{~d}^{2}}
$$

$\sigma^{2}$ is the population variance, work done by Chan et al. [23]; the standard variation was calculated between influenza $A$ strains that is $(\mathrm{HK} 98 / \mathrm{H} 1 \mathrm{~N} 1$ and VN04/H5N1) when used to infect ud-NHBE cells (The ud-NHBE cells were equally susceptible to HK98/H1N1 and VN04/H5N1 virus infection with infection 


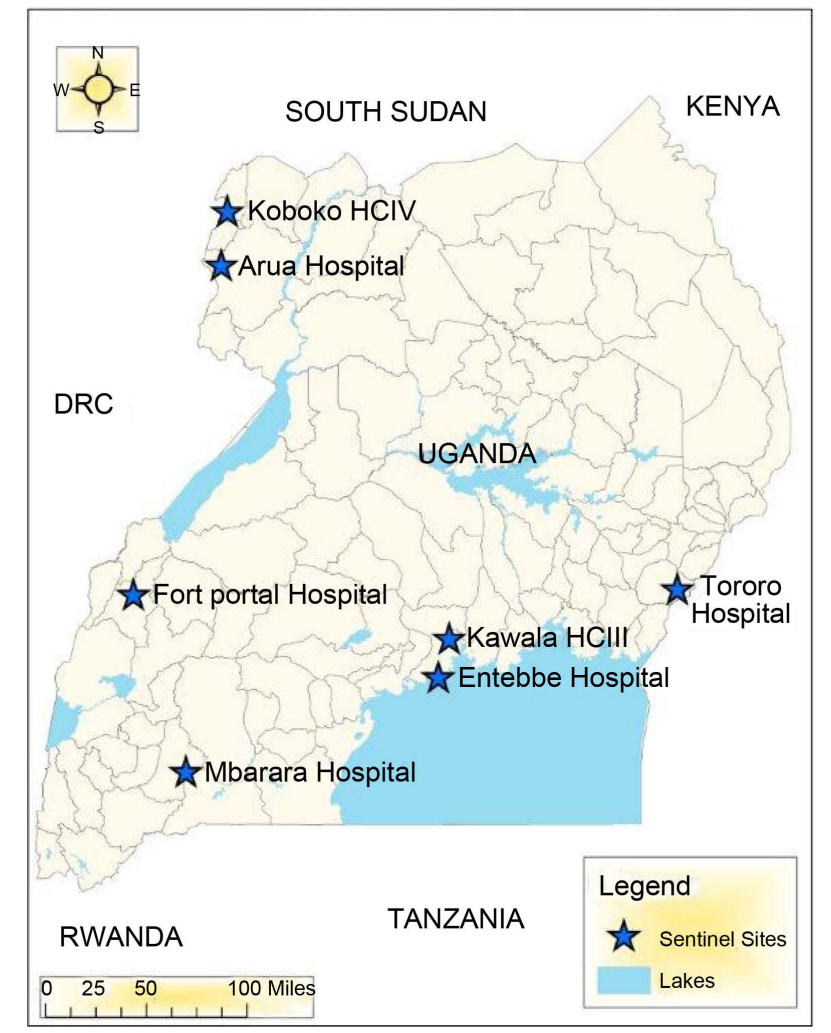

Figure 1. Map of Uganda showing the Influenza sentinel surveillance sites for National Influenza Centre. (Thtinel site location in Uganda).

rates of $95.44 \% \pm 4.55 \%$ in $\mathrm{HK} 98 / \mathrm{H} 1 \mathrm{~N} 1$ and $81 \% \pm 4.17 \%$ in $\mathrm{VN} 04 / \mathrm{H} 5 \mathrm{~N} 1$ infected cells. The average standard deviation for the two different influenza strains is therefore \pm 4.36 . Since there is no other written data comparing standard deviation between influenza $A$ and $B$, this average was used in this study to calculate the sample size.

$\mathrm{d}$ is the difference in this case it was hypothesized to be 5 plaques of $\mathrm{CPE}$ seen in MDCK cells in between influenza A and B as detected.

Therefore, the minimum sample size $n_{i}$ was 24 samples for both influenza A and $\mathrm{B}$, however, for this study, 23 samples were considered for each influenza type, giving a total of 46 samples. This was to cater for the influenza strains: AH1N1, AH3N2, B Yamagata and B Victoria.

\section{Sampling strategy}

The desired sample size for each virus type was 23 samples. The total number of virus containing samples of each type virus $\mathrm{Y}_{\mathrm{A}}$ and $\mathrm{Y}_{\mathrm{B}}$ for the year 2014 was 350 and 150 respectively, where:

$\mathrm{Y}_{\mathrm{A}}=$ total influenza type $\mathrm{A}$ viruses archived

$\mathrm{Y}_{\mathrm{B}}=$ total influenza type $\mathrm{B}$ viruses archived

The samples were archived and stored in $-80^{\circ} \mathrm{C}$ freezers. Sampling techniques as suggested by Cochran et al. were considered Systematic sampling was done where every $\mathrm{Y}_{\mathrm{A}} / 23$ for influenza $\mathrm{A}$ collection required to pick every first and subsequent 15 th sample from the storage box while $Y_{B} / 23$ for influenza $B$ required the first virus vial and every subsequent 6 th virus vial in the influenza $B$ 
storage box. There was no blinding, if the chosen sample was found to fall in the exclusion criteria, it was rejected and the subsequent sample chosen. If a sample was found to be missing, then the subsequent sample was chosen.

All vials archived as influenza A and B were eligible, however, we excluded all vials that were noted to leak, lacked labelling or had inadequate sample volume.

\section{Laboratory methods}

Growth and maintenance of MDCK cell cultures

MDCK cell growth media was EMEM medium (Sigma-Aldrich, USA) supplemented with $0.6 \mu \mathrm{g} / \mathrm{ml}$ penicillin, $60 \mu \mathrm{g} / \mathrm{ml}$ streptomycin, $2 \mathrm{mM}$ L-glutamine, and $20 \mathrm{mM}$ HEPES buffer together with $10 \%$ fetal bovine serum (FBS). MDCK cells were retrieved from $-170^{\circ} \mathrm{C}$ liquid nitrogen, thawed in a water bath at $37^{\circ} \mathrm{C}$ and revived using growth medium and then differentiated using growth medium in a T25 flask incubated at $37^{\circ} \mathrm{C}$ for 3 days. Cells were split and seeded to other flasks using Trypsin-EDTA and growth media and maintained in an incubator at $37^{\circ} \mathrm{C}$ for 3 days. Maintenance medium which constituted growth medium supplements but with replacement of FBS with $7.5 \%$ BSA was used to maintain MDCK cells at the constant phase of the growth cycle. All MDCK growth and maintenance procedures followed recommendations of the WHO and CDC Atlanta influenza virus culture and isolation manuals [24].

\section{Influenza virus isolation and culture in MDCK cells}

Influenza viruses were inoculated onto grown ( $85 \%$ to $90 \%$ confluence) MDCK cells. These cells were grown in T25 $\mathrm{cm}^{2}$ tissue flasks using growth medium. Inoculated cells were maintained using maintenance media and the virus was harvested after 10 days of incubation at $37^{\circ} \mathrm{C}$.

\section{Measurement of influenza virus induced cytokine responses in MDCK} cells

Immunological cytokine responses were analyzed using Enzyme linked immunosorbent assay (ELISA) for the detection of Interferon gamma (IFN- $\gamma$ ), and IL-10. A standard operating protocol adopted from Leinco Technologies for indirect ELISAs was followed (See Appendix. SOP for Indirect ELISA by Leinco Technologies).

\section{Data management}

The data generated (HA titres and ELISA OD values) was recorded in a laboratory book and subsequently double entered into a data capture tool (Excel sheet) and validated for consistence and error minimization. The data was exported to SSPSS v19, 2013 software produced by SPSS Inc. for analysis.

\section{Data Analysis}

The alternative hypothesis, that "there is a difference in the amount soluble factors produced by MDCK cells upon exposure to different influenza virus types", was accepted at a $\mathrm{p}$ value of $\leq 0.05$ after the quantitative value of the difference in means of the cytokines obtained from the ELISAs.

Ethical Approval: Ethical approval was obtained from the Institution Review Board of Makerere University Higher Degree Research and Ethics committee (HDREC). 
To determine and characterize Influenza type A and type B-dependent cytokine responses induced in MDCK cell lines.

The mean of quantities of cytokine responses (IL10, IFN- $\gamma$ ) from infection of each type of virus at different time intervals of 1, 12, 48 and 72 hours was compared using independent samples t-tests as recommended by Koepsell et al. (1991) [25]. Data was statistically analyzed using SPSS v19, 2013 software produced by SPSS Inc.

\section{Influenza virus serotyping}

A total of 46 samples were randomly selected and analyzed for serotype by real time PCR; 23 samples from Influenza A and 23 samples from influenza B. A specimen was considered positive if it showed a critical threshold (CT) value of $<37$ as to standard operating procedures of the department and work done by Balish et al., 2009 [26]. Table 1 summarizes the PCR results of Influenza detection and typing that were chosen for this study. Overall, Influenza type A and B viruses had a representation of 50\% with 12 (52.2\%) samples from influenza A/H1N1 2009 pandemic, 11 (47.8\%) samples of AH3N2, 3 (13\%) from B/Victoria and $20(87 \%)$ samples from $\mathrm{B} /$ Yamagata like lineages.

On average, influenza A viruses had a CT value of 24.458 whereas type B viruses had a CT value of 23.49 .

\section{Results}

\section{Influenza virus cytokine responses in MDCK cells for Interferon gamma}

There was an observed difference in means of Interferon gamma at 1 hour between influenza type A and influenza type B with means of 2.16 and 1.61 as shown in Table 2 respectively. As shown in Table 3, there was no observable difference in means of interferon gamma at 12 and 48 hours, whereas the observed difference in means at 72 hours is biased due to difference in number of influenza virus samples that were able to show CPE at 72 hours. Since most of influenza type A viruses showed CPE before 72 hours, they were harvested earlier thus no isolates were available for ELISA at that hour. This observed difference in means of Interferon gamma at 1 hour between influenza type A and influenza type B was a statistically significant with a p-value of $p \mathbf{0 . 0 2 4}$.

Influenza virus cytokine responses in MDCK cells for Interleukin 10 (IL-10)

There was no observable difference in mean values of IL-10 at 1, 12 and 48 hours, whereas the observed difference in means at 72 hours is biased due to difference in number of influenza virus samples that were able to show CPE at 72 hours as shown in Table 4 . This was because most of influenza type A viruses were harvested earlier before 72 hours when they showed 75\% CPE under a light microscope.

\section{Discussion}

It has been proposed that despite the fact that influenza type A and type B are structurally and functionally similar, they show fundamental differences in the 
Table 1. Positive real time PCR results from clinical nasal and or oral pharyngeal swabs.

\begin{tabular}{|c|c|c|c|c|c|}
\hline ID NUMBER & PCR RESULTS & TYPE & FLU A or B CT & SUBTYPE & FLU A SUBTYPE CT \\
\hline EBB5267 & Positive & A & 20.1508 & AH1pdm & 24.0627 \\
\hline KIS1823 & Positive & A & 28.0689 & AH1pdm & 31.529 \\
\hline KIS1914 & Positive & A & 20.4046 & AH1pdm & 22.0917 \\
\hline KSW4582 & Positive & A & 21.1694 & AH1pdm & 24.5172 \\
\hline KSW4584 & Positive & A & 23.6851 & AH1pdm & 26.8451 \\
\hline EBB5268 & Positive & A & 28.224 & AH1pdm & 32.0139 \\
\hline EBB4940 & Positive & A & 30.0522 & AH1pdm & 29.526 \\
\hline EBB5270 & Positive & A & 23.8371 & AH1pdm & 27.5033 \\
\hline KIS1886 & Positive & A & 19.5673 & AH1pdm & 22.7892 \\
\hline KIS1888 & Positive & A & 22.2155 & AH1pdm & 25.275 \\
\hline KIS1887 & Positive & A & 26.3275 & AH1pdm & 29.6852 \\
\hline KSW4546 & Positive & A & 28.6087 & AH1pdm & 31.9266 \\
\hline KSW4514 & Positive & A & 28.8582 & $\mathrm{AH} 3$ & 23.8736 \\
\hline KIS1904 & Positive & A & 25.8249 & AH3 & 26.7868 \\
\hline NSY0028 & Positive & A & 23.7724 & $\mathrm{AH} 3$ & 18.0847 \\
\hline KIS1861 & Positive & A & 25.0297 & $\mathrm{AH} 3$ & 25.4141 \\
\hline KIS1879 & Positive & A & 24.4485 & $\mathrm{AH} 3$ & 26.0529 \\
\hline KIS1885 & Positive & A & 26.3055 & $\mathrm{H} 3$ & 26.3054 \\
\hline KIS1847 & Positive & A & 24.8081 & $\mathrm{AH} 3$ & 25.1074 \\
\hline KIB0041 & Positive & A & 23.7884 & $\mathrm{AH} 3$ & 25.4105 \\
\hline KSW4471 & Positive & A & 27.5052 & $\mathrm{AH} 3$ & 24.4647 \\
\hline KIS1875 & Positive & A & 17.3585 & $\mathrm{AH} 3$ & 16.0132 \\
\hline KIS1860 & Positive & A & 22.5289 & $\mathrm{AH} 3$ & 22.7223 \\
\hline FTL1385 & Positive & B & 17.9911 & B Yamagata & 18.1594 \\
\hline KIS1918 & Positive & B & 25.7773 & B Yamagata & 27.0966 \\
\hline KBK1223 & Positive & B & 25.5617 & B Yamagata & 25.2803 \\
\hline EBB4972 & Positive & B & 26.0697 & B Yamagata & 26.4643 \\
\hline KIS2072 & Positive & B & 25.4578 & B Yamagata & 25.3051 \\
\hline KIS2073 & Positive & B & 25.0265 & B Yamagata & 24.0821 \\
\hline KSW4745 & Positive & B & 22.7811 & B Yamagata & 21.6641 \\
\hline KSW4746 & Positive & B & 22.1219 & B Yamagata & 19.7473 \\
\hline MBA0907 & Positive & B & 21.9331 & B Yamagata & 23.1047 \\
\hline FTL1369 & Positive & B & 26.1814 & B Yamagata & 25.7938 \\
\hline EBB5272 & Positive & B & 23.3427 & B Yamagata & 24.4343 \\
\hline KSW4807 & Positive & B & 22.8794 & B Victoria & 23.1269 \\
\hline KIS2086 & Positive & B & 19.7218 & B Yamagata & 20.1895 \\
\hline KIS2085 & Positive & B & 25.5406 & B Yamagata & 25.1388 \\
\hline KIS1986 & Positve & B & 19.5334 & B Victoria & 21.9836 \\
\hline EBB5269 & Positive & B & 23.0148 & B Yamagata & 24.0086 \\
\hline TOR1700 & Positive & B & 18.1636 & B Yamagata & 19.327 \\
\hline KBK1802 & Positive & B & 16.4278 & B Yamagata & 16.2451 \\
\hline TOR1520 & Positive & B & 21.2546 & B Yamagata & 22.4505 \\
\hline KSW4479 & Positive & B & 26.2027 & B Yamagata & 27.1021 \\
\hline KSW4483 & Positive & B & 25.073 & B Victoria & 26.0024 \\
\hline EBB4968 & Positive & B & 28.3921 & B Yamagata & 29.5482 \\
\hline KIS2060 & Positive & B & 31.8194 & B Yamagata & 31.295 \\
\hline
\end{tabular}


Table 2. Mean values for interferon gamma at 1, 12, 48 and 72 hours.

\begin{tabular}{cccccc}
\hline Group Statistics & & & & & \\
\hline & Influenza & $\mathrm{N}$ & Mean & Std. Deviation & Std. Error Mean \\
\hline LOG IFN-g & Influenza A & 23 & 2.158087 & 0.5132277 & 0.1070154 \\
1 hour & Influenza B & 23 & 1.611565 & 0.9840909 & 0.2051971 \\
LOG IFN-g & Influenza A & 23 & 2.209217 & 0.1680755 & 0.0350462 \\
12 hours & Influenza B & 23 & 1.947391 & 0.7880262 & 0.1643148 \\
LOG IFN-g & Influenza A & 23 & 2.179739 & 0.1981717 & 0.0413217 \\
48 hours & Influenza B & 23 & 1.995826 & 0.6678903 & 0.1392648 \\
LOG IFN-g & Influenza A & 1 & 0.000000 &. &. \\
72 hours & Influenza B & 11 & 0.964091 & 1.1210373 & 0.3380055 \\
\hline
\end{tabular}

Table 3. Independent t-test for comparison of means of interferon gamma at 1, 12, 48 and 72 hours with their 2 tailed statistical significance.

\begin{tabular}{|c|c|c|c|c|c|c|c|c|}
\hline \multicolumn{9}{|c|}{ Independent Samples Test } \\
\hline & & \multicolumn{4}{|c|}{$\begin{array}{c}\text { Levene's Test for } \\
\text { Equality of Variances }\end{array}$} & \multicolumn{3}{|c|}{ t-test for Equality of Means } \\
\hline & & \multirow{2}{*}{ Sig. } & \multirow{2}{*}{ df } & \multirow{2}{*}{$\begin{array}{c}\text { Sig. } \\
(2 \text {-tailed })\end{array}$} & \multirow{2}{*}{$\begin{array}{c}\text { Mean } \\
\text { Difference }\end{array}$} & \multirow{2}{*}{$\begin{array}{l}\text { Std. Error } \\
\text { Difference }\end{array}$} & \multicolumn{2}{|c|}{ 95\% Confidence Interval of the Difference } \\
\hline & & & & & & & Lower & Upper \\
\hline \multirow{2}{*}{$\begin{array}{c}\text { LOG IFN-g } \\
1 \text { hour }\end{array}$} & $\begin{array}{c}\text { Equal variances } \\
\text { assumed }\end{array}$ & 0.000 & 44 & 0.023 & 0.5465217 & 0.2314264 & 0.0801126 & 1.0129309 \\
\hline & $\begin{array}{l}\text { Equal variances } \\
\text { not assumed }\end{array}$ & & 33.143 & 0.024 & 0.5465217 & 0.2314264 & 0.0757585 & 1.0172850 \\
\hline \multirow{2}{*}{$\begin{array}{l}\text { LOG IFN-g } \\
12 \text { hours }\end{array}$} & $\begin{array}{l}\text { Equal variances } \\
\text { assumed }\end{array}$ & 0.004 & 44 & 0.126 & 0.2618261 & 0.1680107 & -0.0767772 & 0.600429 \\
\hline & $\begin{array}{l}\text { Equal variances } \\
\text { not assumed }\end{array}$ & & 23.997 & 0.132 & 0.2618261 & 0.1680107 & -0.0849329 & 0.6085851 \\
\hline \multirow{2}{*}{$\begin{array}{c}\text { LOG IFN-g } \\
48 \text { hours }\end{array}$} & $\begin{array}{l}\text { Equal variances } \\
\text { assumed }\end{array}$ & 0.033 & 44 & 0.212 & 0.1839130 & 0.1452658 & -0.1088509 & 0.4766770 \\
\hline & $\begin{array}{l}\text { Equal variances } \\
\text { not assumed }\end{array}$ & & 25.844 & 0.217 & 0.1839130 & 0.1452658 & -0.1147729 & 0.4825990 \\
\hline \multirow{2}{*}{$\begin{array}{l}\text { LOG IFN-g } \\
72 \text { hours }\end{array}$} & $\begin{array}{l}\text { Equal variances } \\
\text { assumed }\end{array}$ & · & 10 & 0.429 & -0.9640909 & 1.1708853 & -3.5729859 & 1.6448041 \\
\hline & $\begin{array}{c}\text { Equal variances } \\
\text { not assumed }\end{array}$ & & . & . & -0.9640909 & . & . & . \\
\hline
\end{tabular}

ways in which the host recognizes these pathogens [3]. In this study, the aim was to determine factors that influence the preferential isolation of influenza type $\mathrm{B}$ over Influenza type A in MDCK cell line cultures. This was done by measuring the replicative fitness of Influenza type A and B in MDCK cell line cultures and characterizing Influenza type A and type B-dependent cytokine responses induced in MDCK cell lines. We sought to understand why influenza type B virus expressed early during cell infection, whether there were differences in range and magnitude of cytokines elicited by influenza type A and B, and if the difference was associated with the virulence of the virus.

Characterization of Influenza type A and type B-dependent cytokine 
Table 4. Mean values for interleukin 10 (IL-10) at 1, 12, 48 and 72 hours.

\begin{tabular}{cccccc}
\hline Group Statistics & & & & & \\
& Influenza & $\mathrm{N}$ & Mean & Std. Deviation & Std. Error Mean \\
\hline LOG IL-10 & Influenza A & 23 & 1.507696 & 0.7384569 & 0.1539789 \\
1 hour & Influenza B & 23 & 1.343304 & 0.7738930 & 0.1613678 \\
LOG IL-10 & Influenza A & 23 & 0.781652 & 0.8582243 & 0.1789521 \\
12 hours & Influenza B & 23 & 0.751652 & 0.8343410 & 0.1739721 \\
LOG IL-10 & Influenza A & 23 & 0.592870 & 0.8427791 & 0.1757316 \\
48 hours & Influenza B & 23 & 0.577174 & 0.7543604 & 0.1572950 \\
LOG IL-10 & Influenza A & 2 & 0.000000 & 0.0000000 & 0.0000000 \\
72 hours & Influenza B & 11 & 0.548909 & 0.7653110 & 0.2307499 \\
\hline
\end{tabular}

\section{responses induced in MDCK cell lines}

Available research shows that influenza virus type B activates the interferon regulatory factor-3 (IRF 3)-dependent IFN responses much faster than influenza type A [3], a finding supporting the faster restriction and clearance of influenza type B virus. The IRF 3 is part of a large transcription factor family which has IRF 1 - 9, and these are involved in regulation of cell cycle, apoptosis and tumor suppression [27]. Interferons have been implicated to cause increased disease severity during influenza infections [28] while suppressing viral replication. It is also important to note that the most commonly implicated IFNs are the type I (IFN $\alpha$ and IFN $\beta$ ) and type III IFN (IFN $\lambda$ ) in influenza infection [29]. Here we found evidence that type II IFNs are elicited differently in MDCK cells during influenza type A and B virus infection, with the former inducing higher amounts of IFN $\gamma$. In this research, we concur with Baskin et al. [28] and Kash et al. 2006 [30], that highly pathogenic viruses will be associated with excessive pro-inflammatory cytokine response, as is seen in the first hour of infection with influenza type A. With the desire to examine if anti-inflammatory cytokine IL-10 will give an insight why there is preferential isolation of influenza type $B$ over type A, the mean difference of IL-10 between influenza type A and type B was measured and found to be $\mathbf{6 1}$ and 50 respectively. This did not give any statistical significance, $\boldsymbol{p} \mathbf{0 . 3 3 4}$, in the mean values of the viruses, implying that this cytokine has no role in the preferential isolation of influenza type B over type A. There is now evidence that influenza $A$ virus does not require a large viral load to cause severe disease but it is not yet certain why there is a preferential isolation of influenza $B$ a less virulent and less pathogenic strain compared to influenza type A in MDCK cells. To better understand this phenomenon, it is suggested to probe further using mean difference in the secretion of IL-4 another known anti-inflammatory cytokine.

\section{Limitations}

The specimens used in this study had been collected over a period of one year. They included 23 samples each for influenza type A and type B making a total of 46 samples. Each of these virus types included two different strains: AH1N1 pandemic 2009 and AH3N2 strains for influenza type A and also B Victoria and 
B Yamagata strains for influenza type B. Each of these strains may have had a different reaction in MDCK cells but this was not investigated in this study.

\section{Conclusion}

This study provided evidence that type II IFNs (IFN- $\gamma$ ) may play an important role in the pathogenesis and virulence of influenza type A virus in MDCK cells, a finding unique to this study. To a lesser extent, evidence was provided that antiinflammatory cytokines may not necessarily be playing a role in the preferential infectivity of MDCK cells by influenza type B viruses, a less virulent type over influenza type A.

\section{Recommendations}

It is greatly desirable to further understand the cause of the preferential isolation of influenza type B over influenza type A in MDCK cells. A future study focusing on IL-4 cytokine and any other immunological aspect of the virus would bring more light to the matter.

\section{Acknowledgements}

Special thanks to Prof. Julius Lutwama who availed the National Influenza Center laboratories where this research was carried out from.

\section{References}

[1] Donis, R.O. and ICCW Group (2014) Performance Characteristics of Qualified Cell Lines for Isolation and Propagation of Influenza Viruses for Vaccine Manufacturing. Vaccine, 32, 6583-6590. https://doi.org/10.1016/j.vaccine.2014.06.045

[2] Österlund, P., et al. (2012) Incoming Influenza A Virus Evades Early Host Recognition, While Influenza B Virus Induces Interferon Expression Directly upon Entry. Journal of Virology, 86, 11183-11193. https://doi.org/10.1128/JVI.01050-12

[3] Aichinger, G., et al. (2015) Phase I/II Randomized Double-Blind Study of the Safety and Immunogenicity of a Nonadjuvanted Vero Cell Culture-Derived Whole-Virus H9N2 Influenza Vaccine in Healthy Adults. Clinical and Vaccine Immunology, 22, 46-55. https://doi.org/10.1128/CVI.00275-14

[4] Chanock, R., et al. (1972) A Revised System of Influenza Virus Nomenclature: A Report of the WHO Study Group on Classification. Virology, 47, 854-856. https://doi.org/10.1016/0042-6822(72)90580-6

[5] Kamps, B.S. and Reyes-Terán, G. (2006) Influenza Report 2006. Edited B. S. Kamps, C. Hoffmann and Wolfgang Preiser, Printed by Drunckhaus, SUDGMbH \& Co., ISBN 3-924774-51-X, p. 17-47.

[6] Taubenberger, J.K., et al. (2005) Characterization of the 1918 Influenza Virus Polymerase Genes. Nature, 437, 889-893. https://doi.org/10.1038/nature04230

[7] Tumpey, T.M., et al. (2005) Characterization of the Reconstructed 1918 Spanish Influenza Pandemic Virus. Science, 310, 77-80.

https://doi.org/10.1126/science.1119392

[8] CDC (2005) Centers for Disease Control. Prevention and Control of Influenza Recommendations of the Advisory Committee on Immunization Practices (ACIP). $M M W R$, 54, 1-40. http://www.cdc.gov/mmwr/preview/mmwrhtml/rr5408a1.htm 
[9] Balinandi, S., et al. (2013) The Viral Aetiology of Influenza-Like Illnesses in Kampala and Entebbe, Uganda, 2008: Original Research. African Journal of Laboratory Medicine, 2, 1-5. https://doi.org/10.4102/ajlm.v2i1.65

[10] Van Reeth, K. (2000) Cytokines in the Pathogenesis of Influenza. Veterinary Microbiology, 74, 109-116. https://doi.org/10.1016/S0378-1135(00)00171-1

[11] Hayden, F.G., et al. (1998) Local and Systemic Cytokine Responses during Experimental Human Influenza A Virus Infection. Relation to Symptom Formation and Host Defense. Journal of Clinical Investigation, 101, 643-649. https://doi.org/10.1172/JCI1355

[12] Skoner, D.P., Gentile, D.A., Patel, A. and Doyle, W.J. (1999) Evidence for Cytokine Mediation of Disease Expression in Adults Experimentally Infected with Influenza A Virus. Journal of Infectious Diseases, 180, 10-14. https://doi.org/10.1086/314823

[13] Peper, R.L. and Van Campen, H. (1995) Tumor Necrosis Factor as a Mediator of Inflammation in Influenza A Viral Pneumonia. Microbial Pathogenesis, 19, 175183. https://doi.org/10.1006/mpat.1995.0056

[14] Kurokawa, M., Imakita, M., Kumeda, C.A. and Shiraki, K. (1996) Cascade of Fever Production in Mice Infected with Influenza Virus. Journal of Medical Virology, 50, 152-158. https://doi.org/10.1002/(SICI)1096-9071(199610)50:2<152::AID-JMV8>3.0.CO;2-9

[15] Moran, T.M., et al. (1996) Interleukin-4 Causes Delayed Virus Clearance in Influenza Virus-Infected Mice. Journal of Virology, 70, 5230-5235.

[16] Arilahti, V., Mäkelä, S.M., Tynell, J., Julkunen, I. and Österlund, P. (2014) Novel Avian Influenza A (H7N9) Virus Induces Impaired Interferon Responses in Human Dendritic Cells. PLoS ONE, 9, e96350. https://doi.org/10.1371/journal.pone.0096350

[17] Dauber, B., et al. (2009) Influenza B Virus Ribonucleoprotein Is a Potent Activator of the Antiviral Kinase PKR. PLoS Pathogens, 5, e1000473. https://doi.org/10.1371/journal.ppat.1000473

[18] Marshall, D.R., et al. (2005) Effector CD8+ T Cells Recovered from an Influenza Pneumonia Differentiate to a State of Focused Gene Expression. Proceedings of the National Academy of Sciences of the United States of America, 102, 6074-6079. https://doi.org/10.1073/pnas.0501960102

[19] Xing, Z., et al. (2008) Modulation of the Immune Responses in Chickens by LowPathogenicity Avian Influenza Virus H9N2. Journal of General Virology, 89, 12881299. https://doi.org/10.1099/vir.0.83362-0

[20] Ilyushina, N.A., et al. (2012) Comparative Study of Influenza Virus Replication in MDCK Cells and in Primary Cells Derived from Adenoids and Airway Epithelium. Journal of Virology, 86, 11725-11734. https://doi.org/10.1128/JVI.01477-12

[21] Kamps, B.S., Hoffmann, C. and Preiser, W. (2006) Influenza Report 2006.

[22] WHO (2014) Global Epidemiological Surveillance Standards for Influenza.

[23] Chan, R.W., et al. (2010) Influenza H5N1 and H1N1 Virus Replication and Innate Immune Responses in Bronchial Epithelial Cells Are Influenced by the State of Differentiation. PLoS ONE, 5, e8713. https://doi.org/10.1371/journal.pone.0008713

[24] INFL, W.A. and Manu, U. (2002) WHO Manual on Animal Influenza Diagnosis and Surveillance. World Health Organization, Geneva.

[25] Koepsell, T.D., et al. (1991) Data Analysis and Sample Size Issues in Evaluations of Community-Based Health Promotion and Disease Prevention Programs: A MixedModel Analysis of Variance Approach. Journal of Clinical Epidemiology, 44, 701713. https://doi.org/10.1016/0895-4356(91)90030-D 
[26] Balish, A., et al. (2009) Evaluation of Rapid Influenza Diagnostic Tests for Detection of Novel Influenza A (H1N1) Virus-United States, 2009. Morbidity and Mortality Weekly Report, 58, 826-829.

[27] Hiscott, J. (2007) Triggering the Innate Antiviral Response through IRF-3 Activation. Journal of Biological Chemistry, 282, 15325-15329.

https://doi.org/10.1074/jbc.R700002200

[28] Baskin, C.R., et al. (2009) Early and Sustained Innate Immune Response Defines Pathology and Death in Nonhuman Primates Infected by Highly. Proceedings of the National Academy of Sciences of the United States of America, 106, 3455-3460. https://doi.org/10.1073/pnas.0813234106

[29] Killip, M.J., Fodor, E., and Randall, R.E. (2015) Influenza Virus Activation of the Interferon System. Virus Research, 209, 11-22. https://doi.org/10.1016/j.virusres.2015.02.003

[30] Kash, J.C., et al. (2006) Genomic Analysis of Increased Host Immune and Cell Death Responses Induced by 1918 Influenza Virus. Nature, 443, 578-581.

https://doi.org/10.1038/nature05181 


\section{Appendix}

\section{List of Abbreviations and Acronyms}

HA

MDCK

ELISA

bent Assay

IL-10

$\operatorname{IFN} g(\gamma)$

NIC

UVRI

tute

CPE .

ILI

SARI

fection

NK cells

IRF

PBS

EMEM

Medium

Standard Operating Procedure for Indirect Antigen ELISA Adapted from

\section{LEINCO Technologies}

\section{Principle}

IgG antibody capture enzyme-linked immunosorbent assay provides a useful method for detection of response to infection by an organism. Specimen (antigen) is coated on 96-well plates. This is followed sequentially by the specific antigen. The presence of antigen is detected by using enzyme-conjugated antibody, and a colorimetric result is generated by the interaction of the enzyme and a chromogenic substrate.

\section{Protocol}

All virus containing supernatants to be tested should be heat-inactivated for 30 minutes at $56^{\circ} \mathrm{C}$ prior to testing. After heat-inactivation, store samples at $4^{\circ} \mathrm{C}$ until analysis. Following completion of all serological testing, sample may be stored at $-70^{\circ} \mathrm{C}$ to $-80^{\circ} \mathrm{C}$.

A. Materials/Equipment needed for both protocols:

a. Microplate washer

b. Microplate reader

c. $37^{\circ} \mathrm{C}$ Incubator

d. Single and multi-channel pipettors

e. Reagent reservoirs

B. IgG ELISA Protocol

a. Protocol-Specific Reagents

i. Coating buffer: Carbonate/bicarbonate buffer $\mathrm{pH} 9.6-1.59 \mathrm{~g} \mathrm{Na}_{2} \mathrm{CO}_{3}+2.93$ $\mathrm{g} \mathrm{NaHCO}_{3}$ diluted in $1 \mathrm{~L}$ water. Coating buffer is available as a powder from 
commercial sources.

ii. Wash buffer: Phosphate buffered saline (PBS), 0.05\% Tween 20, pH 7.2. PBS is available in powdered form from multiple commercial sources.

iii. Blocking buffer: PBS/5\% milk/0.5\% Tween 20

iv. Stop solution: $1 \mathrm{~N} \mathrm{H}_{2} \mathrm{SO}_{4}$.

v. Coating antibody: Goat anti-canine IgG. R\&D Biotechne

vi. Viral antigen: Sucrose-acetone extracted suckling mouse brain viral antigens or infected MDCK cell antigen, non-infectious, previously titrated.

vii. Normal antigen: Sucrose-acetone extracted suckling mouse brain antigen from mock-infected animals or extracted mock-infected MDCK cell antigen, depending on source of viral antigen.

viii. Detecting antibody conjugate: Horseradish peroxidase conjugated monoclonal antibody, previously tittered.

ix. Substrate: 3, 3'5, 5' tetramethylbenzidine base (TMB-ELISA). Gibco cat\# 15980-0414

x. Plates: Immulon II HB flat-bottomed 96 well plates. Dynatech Technologies cat\# 3455

xi. Ziploc bags, paper towels

b. Procedure

i. Using a fine-tipped permanent marker, number and label the plates. Identify the location of each clinical specimen by using the appropriate laboratory code number. To keep timing of reagent addition consistent, process plates in the order that they are numbered during all steps of the procedure. Plates should be kept in an enclosed, humidified environment during all incubation times with the exception of the coating step. A large Ziploc bag containing a moist paper towel works well for this purpose.

ii. Coat the wells of 96 well plates with $75 \mu$ per well of antigen diluted 1:2000 in coating buffer $\mathrm{pH}$ 9.6. Incubate at $4^{\circ} \mathrm{C}$ overnight.

iii. Coat the desired wells with the positive control in dilutions as stated in the insert, include wells for a negative control.

iv. Dump out the coating antibody and blot plates on paper towels.

v. Block plates with $200 \mu \mathrm{l}$ blocking buffer per well. Incubate at room temperature for 30 minutes.

vi. Wash wells $3 \mathrm{X}$ with wash buffer by using an automatic plate washer. Wells should be filled to the top each cycle $(300 \mu \mathrm{L})$.

vii. Add $50 \mu \mathrm{l}$ per well of the antibody diluted 1:400 in wash buffer to a block of 6 wells.

viii. Wash $3 \mathrm{X}$.

ix. Add $50 \mu \mathrm{l}$ per well of horseradish peroxidase-conjugated monoclonal antibody, diluted in blocking buffer, according to a previous titration. Incubate 1 hour at $37^{\circ} \mathrm{C}$ in a humid chamber.

x. Turn on plate reader to warm up, and remove TMB from refrigerator.

xi. Wash plates $3 \mathrm{X}$ twice. Turn the plates $180^{\circ}$ in the washer after the first series of 5 cycles. This promotes consistent results. 
xii. While the plate is at room temperature, add $75 \mu \mathrm{l}$ per well of TMB substrate to all wells. Immediately cover plates to block out light. Incubate at room temperature for 10 minutes. A blue color will develop in antigen-positive wells.

xiii. Add $75 \mu \mathrm{l}$ per well of stop solution to all wells. The wells that were blue will now change to a yellow color. Allow plates to sit at room temperature for 1 minute. Read plates in microtiter plate reader by using a $450 \mathrm{~nm}$ filter.

xiv. Enter results into ELISA Excel Spreadsheet for result interpretation. If any Quality Control checks do not read "Pass", analysis of all samples on that plate must be repeated. If all Quality Control checks read "Pass", record the results for each sample.

\section{Scientific Research Publishing}

Submit or recommend next manuscript to SCIRP and we will provide best service for you:

Accepting pre-submission inquiries through Email, Facebook, LinkedIn, Twitter, etc. A wide selection of journals (inclusive of 9 subjects, more than 200 journals)

Providing 24-hour high-quality service

User-friendly online submission system

Fair and swift peer-review system

Efficient typesetting and proofreading procedure

Display of the result of downloads and visits, as well as the number of cited articles

Maximum dissemination of your research work

Submit your manuscript at: http://papersubmission.scirp.org/

Or contact ojmm@scirp.org 